\title{
Histopathology of the muscle in rheumatic diseases
}

\author{
S. Barsotti ${ }^{1}, 2$, A. Tripoli ${ }^{1}$, L.E. Pollina ${ }^{3}$, M. Mosca ${ }^{1}$, R. Neri ${ }^{1}$ \\ ${ }^{1}$ Rheumatology Unit, Department of Clinical and Experimental Medicine, University of Pisa; \\ ${ }^{2}$ Department of Medical Biotechnologies, University of Siena, Italy; \\ ${ }^{3}$ Pathology Department, University of Pisa Medical School Hospital, Pisa, Italy
}

\begin{abstract}
SUMMARY
The presence of muscular symptoms is common in rheumatological clinical practice, but often the differential diagnosis between muscular involvement in connective tissue diseases, vasculitis and drug-induced myopathy may be difficult. In addition to clinical assessment, laboratory analysis and instrumental examinations, muscle biopsy may help to clarify the diagnosis in patients with muscular involvement.

The purpose of this review is to provide a critical analysis of the current medical literature on muscular histopathology, to help clinicians to identify when to perform muscular biopsy and to provide a practical guide to a better understanding of the pathology report. Moreover, we provide an overview of the muscular involvement and the most common histopathological findings in rheumatic diseases.
\end{abstract}

Key words: Myositis; Muscle; Muscular biopsy; Histopathology.

Reumatismo, 2018; 70 (3): 133-145

\section{INTRODUCTION}

M uscular symptoms may be frequently observed in routine rheumatology clinical practice. Although histopathological data should always be integrated by clinical assessment, laboratory analysis (muscle necrosis enzymes) and electrophysiological and imaging examinations, muscle biopsy plays a crucial role in the assessment of muscle involvement in different rheumatic diseases, and is useful for the differential diagnosis, particularly between inflammatory, metabolic or necrotizing diseases (1).

\section{SELECTION OF THE PATIENT, MUSCULAR SITE AND BIOPSY TECHNIQUE}

A muscular biopsy should be planned only after a complete clinical and instrumental assessment of the patient, having ensured that the diagnosis could not have been reached with less expensive and/or invasive ways (1).
The presence of muscular symptoms (weakness or pain, cramps, or fatigue with activity) or changes in laboratory data, represent the main indication for a muscle biopsy, although some rheumatological conditions, such as systemic vasculitis, may present pathological changes even in the absence of muscular symptoms (2).

The selection of the muscle on which to perform the biopsy should be primarily based on the distribution of the symptoms: it is important to exclude both a severely involved muscle which has been replaced by fat or connective tissue, and a scarcely affected muscle that might not show sufficient changes. The clinician should choose a muscle with a $4 / 5$ strength, according to the medical research council (MRC), while a muscle with MRC grade $3 / 5$ is often too severely affected $(1,3)$. Both magnetic resonance imaging $(4,5)$ and muscular ultrasound $(6,7)$ may be useful to help select the biopsy site.

Usually, when weakness distribution is proximal, the most frequently biopsied muscles are the quadriceps in the leg and
Corresponding author:

Simone Barsotti

Rheumatology Unit,

University of Pisa

Via Roma, 67 - 56126 Pisa, Italy

E-mail: simone.barsotti.pisa@gmail.com 
the deltoid in the arm. In the upper arm the biopsy of the more proximal muscle (deltoid) seems to be more useful than that of the biceps in identifying possible alterations (3). If the weakness is mainly distal, a more distal limb muscle may be selected (3). The main advantage in trying to limit the biopsies to specific muscles, is that the pathologist needs to be familiar with their normal pattern and with possible changes related to the age of the patient.

Muscle biopsy is normally performed with local anaesthesia, and may be performed with a needle technique, even though some authors strongly suggest performing open biopsies, as they provide a larger sample and enable direct inspection of the muscle, allowing a more precise collection of muscular tissue (8). All histological, histochemical and immunohistochemical studies are performed on frozen material since fixation and wax-embedding distort the fibre architecture. In addition, metabolic and enzyme studies are not possible on this kind of material. If the specimens have to be transported to other sites for analysis, they can be wrapped in a salinemoistened gauze for 1-2 hours to prevent drying (9).

The complications of open and needle muscular biopsy are usually mild (8); the most common complication observed is limited damage to a dermal nerve branch.

\section{MUSCULAR HISTOLOGY}

Not all pathology laboratories can provide good quality in the analysis of muscle histology. Due to the complexity of the analysis, we strongly suggest referring to major academic centres with highly specialized equipment and substantial experience in muscular disorders $(1,10)$.

Usually, muscular biopsy specimens are subdivided in (10):

1) a portion fixed in buffered formalin (for standard haematoxylin-eosin histological analysis);

2) a portion frozen in a controlled manner for histochemical and immunoenzymatic stainings;

3 ) one or more pieces frozen in liquid nitrogen for biochemical and genetic analyses.

Sometimes, a portion may be fixed in glutaraldehyde for electron microscopic analysis. The most used histological and histochemical methods used for routine analysis of muscle biopsy in rheumatic diseases include the following.

\section{Histological}

1) Haematoxylin-eosin (H\&E) stain is used to identify the general structure of the muscle, fibre size, nuclear centralization, inflammation, nerves, blood vessels (11). Normal muscles show several fascicles separated from each other by perimysium. Muscular fibres are uniform in size and shape, with nuclei located at the periphery of the individual muscle cells (12).

2) Gomori trichrome: to identify rimmed vacuoles, mitochondria and to identify type 1-2 fibres (11).

3) Oil red or Sudan Black stains: to identify intracellular and extracellular lipids (1). In normal muscles intracellular lipids are uniformly distributed throughout the intermyofibrillar network (12).

4) Periodic acid-Schiff (PAS): to identify fibres with excess or loss of glycogen (1). In normal muscle glycogen is uniformly distributed in the myofibres (12).

\section{Immunoenzymatic (oxidative enzymes)}

1) Reduced nicotinamide adenine dinucleotide-tetrazolium reductase (NADHTR): to identify pattern-type of the fibres and distribution of mitochondria (11). Type 1 myofibres are darker than type 2. NADH is particularly localized in the mitochondria and should be distributed uniformly throughout the sarcoplasm.

2) Succinic Dehydrogenase (SDH): to identify pattern-type of the fibres and fibres with abnormal mitochondria and the connective tissue (11).

3) Cytochrome c oxidase (COX): to identify differences in mitochondrial number and their distribution in different fibre types. It may also identify fibres with reduced activity (11). 
4) Myosin ATPase: to highlight distribution and involvement of fibre types and their subtypes $(11,12)$.

5) Other useful histoenzymatic stain methods include phosphorylase (to allow differential diagnosis with other myopathies) and alkaline phosphatase that may identify alterations in blood vessels in some inflammatory myopathies (11).

\section{Immunohistochemistry}

Over the last years immunohistochemistry has gained an essential role in the histological evaluation of muscular biopsies, and is now routinely performed. In the evaluation of rheumatic diseases, the most commonly used antibodies are targeted to major histocompatibility complex (MHC) class I (13), complementary membrane attack complex (MAC) $(14,15)$, and to specific cell differentiation markers, such as CD4, CD8, CD3 for T-cells, and CD20 for B-cells (16).

\section{Electronic microscopy}

EM is not a routine procedure in muscular pathology as it is costly, time consuming and requires a specialized laboratory; only in selected circumstances it may be useful in determining a specific diagnosis (17). For example, if there is a strong suspicion of dermatomyositis and the biopsy shows a normal muscle in all light traditional microscopic studies, EM may identify the presence of microtubular inclusions in endothelial cells (18). EM is useful to characterize the abnormalities seen at the light level, and can be used to identify inclusions and/or changes in each organelle (19).

The aspects that should be evaluated in the analysis of a muscular biopsy are reported in Table I (20). With isolated exceptions, such as for example the perifascicular atrophy in dermatomyositis, no findings in a muscle biopsy are pathognomonic for a specific diagnosis and the histopathological picture must be evaluated as a whole.

\section{Rheumatic diseases presenting with muscular involvement}

Several rheumatologic diseases may present with muscular involvement. Furthermore, some drugs frequently prescribed in
Table I - Elements to analyse in a muscle biopsy.

\begin{tabular}{|l|}
\hline Shape, diameter and size of fibres \\
\hline Areas of necrosis \\
\hline Nuclear position (>3\% of nuclear centralization (129)) \\
\hline Presence of inflammatory cells \\
\hline Normal/increased connective tissue \\
\hline Presence/absence of adipose tissue \\
\hline
\end{tabular}

rheumatology, may be responsible for muscular symptoms. The most common causes of muscular involvement in rheumatology practice are reported in Table II; in some of these conditions muscular biopsy may be helpful to clarify the diagnosis.

\section{IDIOPATHIC INFLAMMATORY MYOPATHIES}

Idiopathic inflammatory myopathies (IIM) constitute a heterogeneous group of subacute, chronic or sometimes acute acquired muscle diseases, which have in common the presence of moderate to severe muscle weakness and inflammation on muscle biopsy $(21,22)$.

Inflammatory myopathies are classified on the basis of distinct clinicopathological features in four subtypes: dermatomyositis (DM), polymyositis (PM), necrotizing autoimmune myositis (NAM), and inclusionbody myositis (IBM) (23).

Table II - Rheumatic conditions associated with myositis/myopathy.

\begin{tabular}{|l|}
\hline Connective tissue diseases \\
\hline Idiopathic inflammatory myopathies \\
Polymyositis (PM) \\
Dermatomyositis (DM) \\
Necrotizing autoimmune myopathy (NAM) \\
Inclusion body myositis (IBM) \\
Primary Sjögren's Syndrome (pSS) \\
Systemic Sclerosis (SSc) \\
Systemic Lupus Erythematosus (SLE) \\
Mixed connective tissue disease (MCTD) \\
\hline Vasculitis \\
\hline Behçet's disease \\
ANCA Associated vasculitis \\
Eosinophilic granulomatosis with polyangiitis (EGPA) \\
Microscopic polyangiitis (MP) \\
Granulomatosis with polyangiitis (GPA) \\
Polyarteritis Nodosa (PAN) \\
\hline
\end{tabular}


These disorders have primarily an autoimmune pathogenesis, mediated by cytotoxic $\mathrm{T}$ cells, as in PM and IBM, by a complement-mediated microangiopathy in DM, or by macrophage and autoantibodies in NAM (24).

The histological features of this group of disease are characterized by the presence of inflammatory cell infiltrates with various degrees of degenerative changes in the muscle fibres. Detection of lymphocyte cells is an important diagnostic criterion. MHC-I can be detected by immunohistochemistry in the sarcolemma of muscle fibres. However, the absence of inflammatory infiltrates in a biopsy does not exclude an inflammatory myopathy (for example acute dermatomyositis in childhood) (22).

\section{Dermatomyositis}

DM can occur in both children and adults. Symptoms include distinct skin manifestations accompanying or preceding proximal symmetric muscle weakness. DM may be limited to the skin (amyopathic DM) when the patient's strength appears normal, although subclinical muscle involvement is frequent (25).

Biopsy: The primary antigenic target in $\mathrm{DM}$ is the vascular endothelium of the endomysial capillaries; an early feature that can be seen in DM is a depletion of capillaries. The histological changes are complement-mediated by the activation of the membrane attack complex (MAC), and consist of necrosis of capillaries, perivascular inflammation and ischemic muscle fibre damage. Finally, there is a marked reduction in the number of capillaries per muscle fibres with compensatory dilatation of the lumen of the remaining capillaries $(24,26)$.

In DM the infiltrate cells are predominantly perivascular and perimysial, although in some cases they may be endomysial, with a high number of B cells and CD4+ cells in the perivascular regions and plasmacytoid dendritic cells in the perifascicular regions (27-29). In the perifascicular regions we can also find regenerating and degenerating fibres $(26,30)$.
Perifascicular atrophy, often seen with perivascular and interfascicular infiltrates, is diagnostic of DM (30) and may probably be the consequence of the related hypoperfusion in the perifascicular fibres (26). The muscle fibres undergo necrosis and phagocytosis owing to microinfarcts that lead to hypoperfusion and perifascicular atrophy $(21,31)$.

With immunohistochemistry, blood vessels in DM show deposits of immune complexes and the terminal component of the complement pathway, the MAC. Complementary, immune complexes, IgG and IgM are also seen in necrotic fibres; the muscle fibres in the perifascicular or other random regions can express MHC-I at the surface $(13,32)$.

Furthermore, overexpression of myxovirus resistance protein $\mathrm{A}(\mathrm{MxA})$, one of type 1 interferon-inducible proteins, was observed on biopsied muscle specimens of DM patients in a preferentially perifascicular distribution, but sometimes also diffusely (33). MxA expression in the myofiber cytoplasm may have a higher sensitivity for the diagnosis of DM compared to perifascicular atrophy (34), because some muscle biopsy specimens do not always include perifascicular atrophy, since this latter distributed in a patchy manner (35).

\section{Polymyositis}

Polymyositis (PM) is characterized by subacute onset of proximal symmetric weakness in adults. PM remains a diagnosis of exclusion, when other causes have been ruled out (30).

The inflammation is perivascular and is most typically concentrated in multiple foci within the endomysium; it consists predominantly of CD8+ T cells (23). Typically, lymphocytic infiltrates surround and invade healthy muscle fibres expressing MHC class I antigens (21). In chronic stages the connective tissue is increased (36).

The application of immunohistochemistry for the localization of MCH class I antigens is extremely important in the study of IIMs. In a normal muscle MCH class I antigens can be detected only on blood vessels, but in all inflammatory myopathies there 
is a significant expression on the sarcolemma and internally in several fibres, and is probably induced by cytokines secreted by activated $\mathrm{T}$ cells $(37,38)$. In PM and IBM CD8+ cytotoxic T cells surround and invade healthy-appearing, non-necrotic muscle fibres that aberrantly express MHC class I. The CD8-MHC class I complex is characteristic of polymyositis and inclusion body myositis, and its detection is useful in confirming histological diagnosis. Perifascicular necrosis (necrosis and regenerating fibres mainly located in the periphery of the muscle fascicle) and perimysial connective tissue fragmentation may be a distinctive hallmark of antisynthetase syndrome (34).

\section{Inclusion body myositis}

IBM is distinguished from PM and DM by a more insidious onset, higher incidence in people over 50 years, and a different pattern of muscular weakness with early involvement of distal muscles (31).

Biopsy: there is an important degenerative component, highlighted by the presence of congophilic amyloid deposits within some fibres $(39,40)$; the size of the fibre is variable, with both atrophy and hypertrophy, and no perifascicular atrophy. There is often an increase in internal nuclei and in endomysial connective tissue. Necrosis, with invasion of the fibres by phagocytes and regeneration fibres, is common (29). The typical feature is the presence in muscular fibres of cytoplasmic bodies, autophagic vacuoles, rimmed by basophilic granules that may be evident also with Gomori trichrome stain, and congophilic amyloid deposits (30).

The extent of the inflammatory response is variable; IBM has all the inflammatory features of polymyositis as perivascular inflammation and the CD8-MHC complex.

$\mathrm{CD} 8+$ cytotoxic $\mathrm{T}$ cells that surround and invade healthy-appearing, non-necrotic muscle fibres that aberrantly express MHC class I, are identifiable by immunohistochemistry, as in PM (13).

A large number of proteins have been associated with the vacuoles, including betaamyloid, ubiquitin, apolipoprotein E, phos- phorylated tau. Because many of these are also found in Alzheimer's disease, authors suggest that an important degenerative process may be involved in IBM pathogenesis $(23,29,41)$. In particular, antibodies to phosphorylated tau protein detected by immunohistochemistry, may identify positivity for SMI-310 that seems specific for sporadic IBM in contrast to SMI-31, which may be positive in hereditary IBM (42).

\section{Necrotizing autoimmune myositis}

Necrotising autoimmune myositis (NAM) is a distinct clinical-pathological entity that occurs more frequently than polymyositis, accounting for up to $19 \%$ of all inflammatory myopathies (43). It can occur at any age, but is seen primarily in adults; most patients have antibodies against signal recognition particle (SRP) or against 3-hydroxy-3-methylglutaryl-coenzyme A reductase (HMGCR) (23). NAM has a acute or subacute onset, with very high creatine kinase levels (>1000), causing severe generalised weakness, including neck and respiratory muscles, and interstitial lung disease in patients with anti-SRP antibodies $(44,45)$.

NAM occurs alone or after viral infections, in association with cancer, in patients with connective tissue disorders, or in patients taking statins, in whom the myopathy continues to worsen after statin withdrawal $(23,46)$.

Biopsy: there are significant necrotic and regeneration muscle fibres with minimal or no inflammatory cell infiltration (47). Histological features in NAM are abundant necrotic fibres invaded or surrounded by macrophages, such as the main effector cells. Lymphocytic infiltrates are sparse and MHC class I up-regulation is often prominent beyond the necrotic fibres. Deposition of complement can be found on capillaries (23).

\section{MYOPATHY IN CONNECTIVE TISSUE DISEASES AND RHEUMATOID ARTHRITIS}

\section{Systemic lupus erythematosus}

Muscle manifestations have been often reported in patients with Systemic Lupus 
Erythematosus (SLE); they are mainly represented by myositis and histopathological evidence has been reported in up to $47 \%$ of patients with muscle symptoms (48). The main histopathological feature is represented by perivascular and perimysial inflammatory infiltrates, mainly composed by mononuclear cells. Endomysial involvement has been reported less frequently, without invasion of non-necrotic muscle fibres $(48,49)$. Sarcoplasmic vacuoles may be present, but without PAS positivity (48) and some patients may present vasculitic lesions (49). A predominance of type 1 myofibres may be present as well as type 2 fibre atrophy (48).

In patients with SLE, an immunoglobulin deposition in the sarcolemma, blood vessel walls, or within the fibres themselves may occur in about $30-40 \%$ of cases (49, 50 ) but not necessarily associated with a myositis (50).

Necrotizing autoimmune myopathy with rhabdomyolysis, inflammatory infiltrates and macrophages and necrotic muscle fibres in absence of vasculitis, has been also reported in SLE patients (51).

\section{Mixed connective tissue disease}

Muscular involvement is common in patients with Mixed Connective Tissue Disease (MCTD) (52) and it has also been described in earlier reports of the disease (53). MCTD patients may present myalgias, weakness and elevated muscle enzymes. Muscular biopsy in patients with MCTD may predominantly show perivascular lymphocytic infiltrates $(54,55)$, but perimysial (56) or endomysial infiltrates (54) have also been described. Thus, lymphocytic infiltrates distribution in MCTD are peculiar and share features of both DM and PM (57). In some patients a lymphocytic vasculitis, without vessel necrosis or fibrinoid change, may be present (54). Moreover, vascular necrosis and perifascicular atrophy may be present $(54,57)$. Histochemistry may show a predominance of type I fibres (54), while direct immunofluorescence often may show immunoglobulin (IgM and/or IgG) deposition that may be present in three different patterns: vascular, sarcolemma-basement membrane and fibre pattern (54). Membrane attack complex deposition and HLA class I and II positivity have been described in MCTD patients $(52,57)$.

\section{Systemic sclerosis}

The prevalence of myopathy in Systemic Sclerosis (SSc) patients varies from 5 to $96 \%$ in medical literature (58) and the severity of muscular disease is strictly associated with the disability (59). Histopathological categories include nonspecific myositis, necrotizing myopathy, DM, fibrosis only, and PM (60).

The histological findings of muscle biopsies in SSc patients are non-specific and are virtually indistinguishable from the findings in $\mathrm{PM} / \mathrm{DM}$ patients (61). In the majority of patients, the muscular involvement is characterized by the prevalence of necrotic muscle fibres, muscle inflammation, fibrosis in the perimysium and epimysium, and muscular atrophy (60, 62-64). MHC class I expression is reported in more than half of the patients $(60,62)$. The muscle infiltrates are predominantly characterized by CD8-positive $\mathrm{T}$ cells, in particular in muscles with necrotic fibres (60) and in the perimysium (16), while CD-4 and CD-3 positive cells are less represented (60). In patients with SSc a high number of atrophic fibres staining positive for esterase has been reported; this may represent a peculiar characteristic of patients with SSc that may help to differentiate SSc myopathy from other autoimmune myositis (58). In patients with SSc-PM overlap the number of necrotic muscle fibres is higher compared to PM patients, but the presence of lymphocytic infiltrates, fibrosis and MHC class I positivity are similar to PM (62). In SSc patients an IBM-like disease has rarely been reported (65).

\section{Primary Sjögren's syndrome}

Patients with primary Sjögren's Syndrome (PSS) often complain the presence of myalgias, and a large number of pSS patients, although asymptomatic, may present histopathological evidence of myositis $(66,67)$. A recent large retrospective study reported that $2.24 \%$ of pSS patients presented clinically relevant muscular symptoms (68). 
Muscular morphology in pSS patients may be normal or nearly normal in $20-30 \%$ of patients $(68,69)$; however, the most common abnormal finding is muscular inflammation in $46-72 \%$ of patients $(68,69)$. Inflammatory infiltrates are mainly identified in the perivascular area with a DM-like aspect $(67,69)$, but can also be found in endomysial and perimysial areas $(68,69)$. Moreover, muscular fibre necrosis and endomysial infiltrates (CD3/CD8+) have also been reported, suggesting a PM-like pattern (68). Anecdotally, a peculiar histological pattern has been reported in pSS patients, with germinal centre-like structures, resembling the histological abnormalities that usually occur in salivary glands (70). Immunohistochemical staining may show a decreased COX positivity (68). MHC class I positivity and pathological expression of MAC were respectively reported in $50 \%$ and $75 \%$ of the biopsies (69).

In pSS patients a clinical (71) and genetic (72) association with IBM has been reported, and in some muscular biopsies the presence of rimmed vacuoles, suggesting IBMlike pattern, has been identified $(68,69)$.

\section{Rheumatoid arthritis}

Muscular involvement in patients with Rheumatoid Arthritis (RA) has been often reported, and although it may be predominantly related to treatment, impaired joint flexibility, or sedentary lifestyle (73), it can occasionally present as a definite clinical subset defined as rheumatoid myositis (74). Histological abnormalities in muscular biopsy are common in RA patients, even if clinically asymptomatic for muscular disease (74). Although type II fibre atrophy is the most common abnormality ( 73 , 74), muscle fibre necrosis has also been reported in about $40 \%$ of patients (74). Moreover, interstitial mononuclear cell infiltrates have been reported (74), particularly perivascular B- or T-cell inflammatory infiltrates (73). Endomysial PM-like inflammation has also been reported, with lymphocytes and macrophages invading non necrotic muscle fibres (73). Indirect immunofluorescence may identify a mild $\operatorname{IgG}$ positivity in the muscle, while some patients with rheumatoid myositis may present a moderate or marked IgG positivity in the sarcolemmal membrane (74).

\section{Systemic vasculitis}

In systemic vasculitis, an alteration of muscular perfusion and/or vasculitis (with vascular and perivascular infiltrates) may occur. Moreover, endothelial damage due to vasculitis may produce reduced microcirculation with muscle hypoperfusion (75). Some cases of systemic vasculitis may present with muscular involvement.

\section{Behçet's disease}

Muscle involvement is rarely associated with Behçet's disease (BD). The most common muscle manifestation is myositis ( 75 , 76). Although imaging may be helpful in identifying muscular alteration in BD (77), histopathology is crucial for differential diagnosis. In BD it is usually represented by focal skeletal muscle involvement, ( 75 , 78) but orbital involvement has also been described $(79,80)$.

The muscular biopsy in BD samples typically exhibits perivasculitis $(81,82)$ or necrotizing vasculitis (83), with muscular inflammation presenting as myositis and necrotic foci $(76,81,84,85)$, sometimes with a nodular aspect (84). The cellular infiltrates may be characterized prominently by the presence of granulocytes and monocytes or lymphocytes and monocytes (76). Muscular involvement in BD may sometimes present as muscular atrophy, with histopathological finding of glycogen particles with EM (86), and alteration of normal muscular architecture.

\section{ANCA-associated vasculitis}

Although myalgia is a common feature in patients with Anca-Associated Vasculitis (AAV), typical myositic presentation with muscle weakness is uncommon (87, 88). However, muscular involvement may be present in a large group of patients and may be useful in confirming the diagnosis of vasculitis (2).

In patients with eosinophilic granulomatosis with polyangiitis (EGPA), the presence of typical myositis is uncommon and is de- 
scribed only in a few case reports. In these cases, necrotizing vasculitis with eosinophilic infiltrates in perimysial blood vessels associated with aspecific myopathic signs, was observed (89-91). Several authors have also reported massive eosinophilic infiltrates (91), while eosinophilic giant cells and extravascular granulomas may be present (89). Some authors have described histopathological patterns very similar to classic polymyositis (92). By immunohistochemistry, MHC-1 may be overexpressed (89). Orbital muscle involvement may be present as the only manifestation $(90,93)$.

Microscopic polyangiitis may present with myositis, while muscle histopathology may show association with small-vessel vasculitis (94-97), which may be linked to ischemic infarct-like necrotic changes (95, 97); granuloma may not be present (94).

In Granulomatosis with polyangiitis (GPA), sporadic cases of peripheral (98) and ocular (99) muscular involvement have been reported.

\section{Polyarteritis nodosa}

Muscle involvement is not uncommon in Polyarteritis nodosa (PAN) and clinical aspects include myalgia and muscle weakness (100) that may be similar to PM (101). In some patients, skeletal muscle involvement may represent the only clinically evident manifestation of the disease $(102,103)$, and in asymptomatic patients histology may help in identifying muscular alterations consistent with the diagnosis of PAN (104).

Typical alterations found in PAN are usually represented by vascular segmental inflammatory lesions with lymphocytes, mainly CD4+ cells (105), macrophages and neutrophil infiltrates (106). Vessels may present fibrinoid necrosis with a predominance of neutrophil infiltrates $(105,106)$, while in later stages of the disease cellular infiltrates are usually composed of lymphocytes and macrophages. Neoangiogenesis, vascular remodelling with intimal hyperplasia, fibrotic changes within the vessel wall and microaneurysms are also characteristic in advanced stages $(105,106)$. Muscle fibres may present a marked variation of their di- ameters with both atrophic, hypertrophic and necrotic fibres (107).

\section{DRUG INDUCED MYOPATHIES}

Several drugs usually prescribed in rheumatological clinical practice may cause myopathies with nonspecific clinical symptoms, including asthenia, fatigue, muscular weakness, elevated muscle necrosis enzymes and, sometimes, rhabdomyolysis (10).

Steroids are often used in the treatment of rheumatic diseases and a differential diagnosis between IIMs and steroid myopathy may be difficult (108). Steroids are classically associated with chronic myopathies, and chronic exposure to this drug may induce mild and slowly progressive muscle weakness, occasionally leading to an acute form that may be present with severe and generalized muscle weakness, sometimes with flaccid paralysis $(10,109,110)$. The histopathology of the chronic form shows type IIb fibre atrophy without inflammation or fibre necrosis associated with a variation in fibre size and nuclear centralization (111); in acute myopathy type I myofibre atrophy and fibres necrosis may be present, in addition to type II fibres atrophy $(109,110)$. Chloroquine and, rarely, hydroxychloroquine, may be associated with myopathy with proximal muscle weakness without myalgia (10); the mechanism is still unknown, but it is probably related to the accumulation of the drug in lysosomes, and may also include impaired autophagy (112, 113). Muscle biopsy reveals vacuoles in up to $50 \%$ of the myofibres, particularly in type I fibres (114), and neurogenic muscle atrophy with angulated atrophic fibres and fibre type grouping may be present (10). Acid phosphatase stain may reveal increased lysosomal enzyme activity $(115,116)$.

A prolonged use of colchicines can cause myopathy with progressive proximal muscle weakness, myalgia and CK elevation. Similar to chloroquine and hydroxychloroquine toxicity, muscle biopsy can show vacuoles particularly in type 1 fibres on H\&E stain (117). The vacuoles are of different sizes, and may be empty or contain granular basophilic material (117). 
Cyclosporine may be a rare cause of myopathy characterized by muscle pain and weakness (118). In the few cases described, muscle biopsy showed atrophic fibres, segmental necrosis with accumulation of subsarcolemmal mitochondria and increased amounts of glycogen $(119,120)$. EM may identify lipid vacuoles and increased lysosomal activity.

D-Penicillamine may cause inflammatory myopathy with clinical and histological characteristics similar to idiopathic PM/ DM (121). Moreover, D-penicillamine may be associated with myasthenia gravis; muscular biopsy in these patients may show fibre atrophy, lymphoid aggregates and COX-negative fibres (10).

Statins, lipid lowering drugs inhibiting the 3-hydroxy-3-methylglutaryl-CoA-reductase (HMGCR), are commonly associated with muscular symptoms $(122,123)$. Statin treatment is associated with the following muscular manifestations (124): myalgia, myositis and rhabdomyolysis (with marked CK elevation and possible association with myoglobinuria). Some patients may develop an immune-mediated disease, often associated with antiHMG-CoA reductase autoantibodies (125), that may require immunosuppressive treatment (126).

In statin-induced necrotizing myopathy, muscle biopsy usually identifies a necrotizing myopathy with necrosis of muscle fibres and macrophages infiltrates and myophagocytosis (44), and type II fibre atrophy may be frequently present (127). Typical aspects of mitochondrial dysfunction have been described in some patients, and are reversible with the suspension of the drug (128). MHC class I positivity has been identified in about $50 \%$ of patients with HBGCR autoantibodies (125), but sarcolemmal positivity seems to be specific to statin-induced myositis (44).

\section{CONCLUSIONS}

Muscular damage is frequent in connective tissue diseases and vasculitis. An appropriate diagnostic workup should include an accurate anamnesis, with laboratory and instrumental investigations. Muscular biopsies are very complex and expensive histopathological procedures, but they may represent an irreplaceable diagnostic tool to guide the diagnosis in muscular diseases. Sometimes, despite extensive analysis, it is not possible to identify a specific cause of the muscle alteration: in these cases, close collaboration between an expert muscle pathologist and the clinical team is mandatory to formulate a correct diagnosis.

Conflict of interest: the authors declare they have no conflicts of interest.

\section{REEERENCES}

1. Joyce NC, Oskarsson B, Jin LW. Muscle biopsy evaluation in neuromuscular disorders. Phys Med Rehabil Clin N Am. 2012; 23: 609-31.

2. Nunokawa T, Yokogawa N, Shimada K, et al. The use of muscle biopsy in the diagnosis of systemic vasculitis affecting small to mediumsized vessels: a prospective evaluation in Japan. Scand J Rheumatol. 2015; 9742: 1-5.

3. Lai C-H, Melli G, Chang Y-J, et al. Open muscle biopsy in suspected myopathy: diagnostic yield and clinical utility. Eur J Neurol. 2010; 17: 136-42.

4. Lampa J, Nennesmo I, Einarsdottir H, Lundberg I. MRI guided muscle biopsy confirmed polymyositis diagnosis in a patient with interstitial lung disease. Ann Rheum Dis. 2001; 60: 423-6.

5. van de Vlekkert J, Maas M, Hoogendijk JE, et al. Combining MRI and muscle biopsy improves diagnostic accuracy in subacute-onset idiopathic inflammatory myopathy. Muscle Nerve. 2014. [Epub ahead of print].

6. Walker UA. Imaging tools for the clinical assessment of idiopathic inflammatory myositis. Curr Opin Rheumatol. 2008; 20: 656-61.

7. Nair JR, Nijjar M, Chiphang A, Binymin KA. Ultrasound-guided closed muscle biopsy: a useful tool for rheumatologists. Rheumatol Int. 2013; 33: 799-801.

8. Ton E, Kruize AA. When and how to perform biopsies in a patient with a (suspected) connective tissue disease. Best Pract Res Clin Rheumatol. 2013; 27: 209-36.

9. Dubowitz V, Sewry CA. The procedure of muscle biopsy. Muscle Biops Pratic Approach. 2007; 1: 3-20.

10. Harris BT, Mohila CA. Essential muscle pathology for the rheumatologist. Rheum Dis Clin North Am. 2011; 37: 289-308.

11. Dubowitz V, Sewry CA. Histological and histochemical stains and reactions. Muscle Biops Pratic Approach. 2007; 1: 21-41. 
12. Seidman RJ. Skeletal muscle structure and histology; Published 2015. Available from: http:// emedicine.medscape.com/article/1923188overview Accessed: April 21, 2017.

13. Emslie-Smith AM, Arahata K, Engel AG. Major histocompatibility complex class I antigen expression, immunolocalization of interferon subtypes, and T cell-mediated cytotoxicity in myopathies. Hum Pathol. 1989; 20: 224-31.

14. Cong L, Pu C-Q, Shi Q, et al. Complement membrane attack complex is related with immune-mediated necrotizing myopathy. Int J Clin Exp Pathol. 2014; 7: 4143-9.

15. Braczynski AK, Harter PN, Zeiner PS, et al. C5b-9 deposits on endomysial capillaries in non-dermatomyositis cases. Neuromuscul Disord. 2016; 26: 283-91.

16. Arahata K, Engel AG. Monoclonal antibody analysis of mononuclear cells in myopathies. I: Quantitation of subsets according to diagnosis and sites of accumulation and demonstration and counts of muscle fibers invaded by $\mathrm{T}$ cells. Ann Neurol. 1984; 16: 193-208.

17. Dubowitz V, Seidman RJ. Ultrastructural changes in diseased muscle. Muscle Biops Pratic Approach. 2007; 2: 125-94.

18. De Visser M, Emslie-Smith AM, Engel AG. Early ultrastructural alterations in adult dermatomyositis. Capillary abnormalities precede other structural changes in muscle. J Neurol Sci. 1989; 94: 181-92.

19. Goebel HH, Stenzel W. Practical application of electron microscopy to neuromuscular diseases. Ultrastruct Pathol. 2013; 37: 15-8.

20. Dubowitz V, Sewry CA. Definition of pathological changes seen in muscle biopsies. Muscle Biops Pratic Approach. 2007; 1: 75-123.

21. Dalakas MC. Polymyositis, dermatomyositis, and inclusion-body myositis. N Engl J Med. 1991; 325: 1487-98.

22. Dalakas MC, Hohlfeld R. Polymyositis and dermatomyositis. Lancet. 2003; 362: 971-82.

23. Dalakas MC. Inflammatory muscle diseases. N Engl J Med. 2015; 372: 1734-47.

24. Dalakas MC, Karpati G. The inflammatory myopathies. In: Disorders of voluntary muscle (8th ed). Cambridge: Cambridge University Press. 2010; 427-452.

25. Femia AN, Vleugels RA, Callen JP. Cutaneous dermatomyositis: an updated review of treatment options and internal associations. Am J Clin Dermatol. 2013; 14: 291-313.

26. Dalakas MC. Inflammatory muscle diseases: a critical review on pathogenesis and therapies. Curr Opin Pharmacol. 2010; 10: 346-52.

27. Mammen AL, Casciola-Rosen LA, Hall JC, et al. Expression of the dermatomyositis autoantigen Mi-2 in regenerating muscle. Arthritis Rheum. 2009; 60: 3784-93.

28. Engel AG, Hohlfeld R, Banker B. The polymyositis and dermatomyositis syndrome. In: Engel
AG, Franzini-armstrong C, eds. Myology. New York: MC Graw-Hill. 2008; 1335-1383.

29. Dubowitz V, Sewry CA. Inflammatory miopathies. In: Dubowitz V, Sewry CA, eds. Muscle Biopsty - A Pratical Approach. Saunders. 2006.

30. Dalakas MC. Review: An update on inflammatory and autoimmune myopathies. Neuropathol Appl Neurobiol. 2011; 37: 226-42.

31. Engel AG, Hohlfeld R. The polymyositis and dermatomyositis complex. In: Engel AG, Franzini-Armstrong C, eds. Myology. New York: MC Graw-Hill. 2008; 1335-1383.

32. Karpati G, Pouliot Y, Carpenter S. Expression of immunoreactive major histocompatibility complex products in human skeletal muscles. Ann Neurol. 1988; 23: 64-72.

33. Greenberg SA, Pinkus JL, Pinkus GS, et al. Interferon-alpha/beta-mediated innate immune mechanisms in dermatomyositis. Ann Neurol. 2005; 57: 664-78.

34. Suzuki S, Uruha A, Suzuki N, Nishino I. Integrated diagnosis project for inflammatory myopathies: an association between autoantibodies and muscle pathology. Autoimmun Rev. 2017; 16: 693-700.

35. Iaccarino L, Ghirardello A, Bettio S, et al. The clinical features, diagnosis and classification of dermatomyositis. J Autoimmun. 2014; 4849: $122-7$.

36. Dalakas MC. Muscle biopsy findings in inflammatory myopathies. Rheum Dis Clin North Am. 2002; 28: 779-98, vi.

37. Wiendl H, Hohlfeld R, Kieseier BC. Immunobiology of muscle: advances in understanding an immunological microenvironment. Trends Immunol. 2005; 26: 373-80.

38. Dalakas MC. Mechanisms of disease: signaling pathways and immunobiology of inflammatory myopathies. Nat Clin Pract Rheumatol. 2006; 2: 219-27.

39. Askanas V, Engel WK, Nogalska A. Sporadic inclusion-body myositis: a degenerative muscle disease associated with aging, impaired muscle protein homeostasis and abnormal mitophagy. Biochim Biophys Acta. 2015; 1852: 633-43.

40. Needham M, Mastaglia FL. Inclusion body myositis: current pathogenetic concepts and diagnostic and therapeutic approaches. Lancet Neurol. 2007; 6: 620-31.

41. Dalakas MC. Pathophysiology of inflammatory and autoimmune myopathies. Presse Med. 2011; 40: e237-47.

42. Mirabella M, Alvarez RB, Bilak M, et al. Difference in expression of phosphorylated tau epitopes between sporadic inclusion-body myositis and hereditary inclusion-body myopathies. J Neuropathol Exp Neurol. 1996; 55: 774-86.

43. van der Meulen MFG, Bronner IM, Hoogendi- 
jk JE, et al. Polymyositis: an overdiagnosed entity. Neurology. 2003; 61: 316-21.

44. Stenzel W, Goebel H-H, Aronica E. Review: immune-mediated necrotizing myopathies--a heterogeneous group of diseases with specific myopathological features. Neuropathol Appl Neurobiol. 2012; 38: 632-46.

45. Mammen AL, Chung T, Christopher-Stine L, et al. Autoantibodies against 3-hydroxy3-methylglutaryl-coenzyme A reductase in patients with statin-associated autoimmune myopathy. Arthritis Rheum. 2011; 63: 713-21.

46. Dalakas MC. Necrotising autoimmune myopathy (NAM): antibodies seem to be specific markers in aiding diagnosis. J Neurol Neurosurg Psychiatry. 2016; 87:1037.

47. Suzuki S, Uruha A, Suzuki N, Nishino I. Integrated diagnosis project for inflammatory myopathies: an association between autoantibodies and muscle pathology. Autoimmun Rev. 2017; 16: 693-700.

48. Jakati S, Rajasekhar L, Uppin M, Challa S. SLE myopathy: a clinicopathological study. Int J Rheum Dis. 2015; 18: 886-91.

49. Vizjak A, Perkovic T, Rozman B, et al. Skeletal muscle immune deposits in systemic lupus erythematosus. Correlation with histologic changes, autoantibodies, and clinical involvement. Scand J Rheumatol. 1998; 27: 207-14.

50. Isenber DA, Snaith ML. Muscle disease in systemic lupus erythematosus: a study of its nature, frequency and cause. J Rheumatol. 1981; 8: 917-24.

51. García-Reynoso MJ, Veramendi-Espinoza LE, Ruiz-Garcia HJ. Ascending paresis as presentation of an unusual association between necrotizing autoimmune myopathy and systemic lupus erythematosus. Reumatol Clin. 2014; 10: 183-6.

52. Tasca G, Mirabella M, Berrettini A, et al. Mixed connective tissue disease presenting as a peculiar myositis with poor muscle regeneration. Neurol Sci. 2011; 32: 171-4.

53. Sharp GC, Irvin WS, Tan EM, Gould RG, Holman HR. Mixed connective tissue disease--an apparently distinct rheumatic disease syndrome associated with a specific antibody to an extractable nuclear antigen (ENA). Am J Med. 1972; 52: 148-59.

54. Oxenhandler R, Hart M, Corman L, et al. Pathology of skeletal muscle in mixed connective tissue disease. Arthritis Rheum. 1997; 20: 985-8.

55. Bennett RM, O'Connell DJ. Mixed connective tisssue disease: a clinicopathologic study of 20 cases. Semin Arthritis Rheum. 1980; 10: 25-51.

56. Lundberg I, Nennesmo I, Hedfors E. A clinical, serological, and histopathological study of myositis patients with and without anti-RNP antibodies. Semin Arthritis Rheum. 1992; 22: 127-38.
57. Vianna MAAG, Borges CTL, Borba EF, et al. Myositis in mixed connective tissue disease: a unique syndrome characterized by immunohistopathologic elements of both polymyositis and dermatomyositis. Arq Neuropsiquiatr. 2004; 62: 923-34.

58. Paik JJ. Myopathy in scleroderma and in other connective tissue diseases. Curr Opin Rheumatol. 2016; 28: 631-5.

59. Paik JJ, Wigley FM, Mejia AF, Hummers LK. Independent association of severity of muscle weakness with disability as measured by the health assessment questionnaire disability index in scleroderma. Arthritis Care Res (Hoboken). 2016; 68: 1695-703.

60. Paik JJ, Wigley FM, Lloyd TE, et al. Spectrum of muscle histopathologic findings in fortytwo scleroderma patients with weakness. Arthritis Care Res (Hoboken). 2015; 67: 141625.

61. Lóránd V, Czirják L, Minier T. Musculoskeletal involvement in systemic sclerosis. Presse Med. 2014; 43: e315-28.

62. Bhansing KJ, Lammens M, Knaapen HKA, et al. Scleroderma-polymyositis overlap syndrome versus idiopathic polymyositis and systemic sclerosis: a descriptive study on clinical features and myopathology. Arthritis Res Ther. 2014; 16: R111.

63. Ranque B, Authier F-J, Le-Guern V, et al. A descriptive and prognostic study of systemic sclerosis-associated myopathies. Ann Rheum Dis. 2009; 68: 1474-7.

64. Thompson JM, Bluestone R, Bywaters EG, et al. Skeletal muscle involvement in systemic sclerosis. Ann Rheum Dis. 1969; 28: 281-8.

65. Vemulapalli S, Sharer LR, Hsu VM. Inclusion body myositis in a patient with RNA polymerase III antibody-positive systemic sclerosis. J Rheumatol. 2015; 42: 730-2.

66. Lindvall B, Bengtsson A, Ernerudh J, Eriksson P. Subclinical myositis is common in primary Sjögren's syndrome and is not related to muscle pain. J Rheumatol. 2002; 29: 717-25.

67. Vrethem M, Lindvall B, Holmgren H, et al. Neuropathy and myopathy in primary Sjögren's syndrome: neurophysiological, immunological and muscle biopsy results. Acta Neurol Scand. 1990; 82: 126-31.

68. Colafrancesco S, Priori R, Gattamelata A, et al. Myositis in primary Sjögren's syndrome: data from a multicentre cohort. Clin Exp Rheumatol. 2015; 33: 457-64.

69. Lindvall B, Bengtsson A, Ernerudh J, Eriksson P. Subclinical myositis is common in primary Sjögren's syndrome and is not related to muscle pain. J Rheumatol. 2002; 29: 717-25.

70. Espitia-Thibault A, Masseau A, Néel A, et al. Sjögren's syndrome-associated myositis with germinal centre-like structures. Autoimmun Rev. 2017; 16: 154-8. 
71. Derk CT, Vivino FB, Kenyon L, Mandel S. Inclusion body myositis in connective tissue disorders: case report and review of the literature. Clin Rheumatol. 2003; 22: 324-8.

72. Rojana-udomsart A, Needham M, Luo YB, et al. The association of sporadic inclusion body myositis and Sjögren's syndrome in carriers of HLA-DR3 and the 8.1 MHC ancestral haplotype. Clin Neurol Neurosurg. 2011; 113: 559-63.

73. Ancuța C, Pomîrleanu DC, Anton CR, et al. Rheumatoid myositis, Myth or reality? A clinical, Imaging and histological study. Rom J Morphol Embryol. 2014; 55: 781-5.

74. Halla JT, Koopman WJ, Fallahi S, et al. Rheumatoid myositis - clinical and histologic features and possible pathogenesis. Arthritis Rheum. 1984; 27: 737-43.

75. Finsterer J, Loscher WN, Wanschitz J, et al. Secondary myopathy due to systemic diseases. Acta Neurol Scand. 2016; 134: 388-402.

76. Worthmann F, Bruns J, Türker T, Gosztonyi G. Muscular involvement in Behçet's disease: case report and review of the literature. Neuromuscul Disord. 1996; 6: 247-53.

77. Jo SE, Kim YJ, Lee K-H, et al. Muscular involvement of Behçet's disease: ultrasonography, computed tomography, and magnetic resonance imaging findings. Clin Imaging. 2012; 36: 643-6.

78. Conway R, Bergin D, Carey JJ CR. A case of Behçet's syndrome presenting as focal myositis. Rheumatol. 2012; 51: 975.

79. Chebbi W, Jerbi S, Ammari W, et al. Orbital myositis in Behçet's disease. Jt Bone Spine. 2014; 81: 264.

80. Dursun D, Akova Y, Yucel E. Myositis and scleritis associated with Behcet's disease: an atypical presentation. Ocul Immunol Inflamm. 2004; 12: 329-32.

81. Stubbs AY, Taljanovic MS, Massey BZ, et al. Myonecrosis of Behcet's disease. Skeletal Radiol. 2008; 37: 357-60.

82. Ogose T, Tamaki W, Shinahara K, et al. A case of recurrent myositis as the main manifestation of Behçet disease. Pediatr Int. 2010; 52: 10-3.

83. Kazarians H, Voelter HU, Schwendemann G. Muscular necrotizing vasculitis as the initial manifestation of Behçet's disease. Muscle Nerve. 1999; 22: 430-1.

84. Sarui H, Maruyama T, Ito I, et al. Necrotising myositis in Behçet's disease: characteristic features on magnetic resonance imaging and a review of the literature. Ann Rheum Dis. 2002; 61: 751-2.

85. Yilmaz S, Sanal HT, Cinar M, Karslıoglu Y. Muscle involvement in two Behçet cases: magnetic resonance imaging and histology findings. Jpn J Radiol. 2014; 32: 233-7.

86. Frayha RA, Afifi AK, Bergman RA, Nader S, Bahuth NB. Neurogenic muscular atrophy in Behcet's disease. Clin Rheumatol. 1985; 4: 202-11.
87. Lazzarin P, Presotto F, Polo A. [ChurgStrauss syndrome presenting as polymyositis: report of a case]. Reumatismo. 2009; 61: 140-4.

88. De Vlam K, De Keyser F, Goemaere S, et al. Churg-Strauss syndrome presenting as polymyositis. Clin Exp Rheumatol. 1995; 13: 505-7.

89. Parent M-E, Larue S, Ellezam B. Eosinophilic granulomatosis with polyangiitis (Churg-Strauss syndrome) presenting as diffuse myositis. BMC Musculoskelet Disord. 2014; 15 : 388.

90. Fujii T, Norizuki M, Kobayashi T, et al. A case of eosinophilic orbital myositis associated with CSS. Mod Rheumatol. 2010; 20: 196-9.

91. Uehara M, Hashimoto T, Sasahara E, et al. Churg-Strauss syndrome presenting as myositis following unaccustomed exercise. J Clin Neurosci. 2009; 16: 1232-3.

92. Tutor-Ureta P, Martín Jiménez ML, Bellas C, et al. Polimiositis como forma de presentación de síndrome de Churg-Strauss. Rev Clínica Española. 2011; 211: e25-7.

93. Billing K, Malhotra R, Selva D, Dodd T. Orbital myositis in Churg-Strauss syndrome. Arch Ophthalmol. 2004; 122: 393.

94. Sassi S Ben, Ghorbel I Ben, Mizouni H, et al. Microscopic polyangiitis presenting with peripheral and central neurological manifestations. Neurol Sci. 2011; 32: 727-9.

95. Benz N, Daikeler T, Frank S, et al. Three cases of primary small vessel vasculitis of the skeletal muscle-an own entity. Case Reports. 2011; 2011: bcr0820114631bcr0820114631.

96. Nagai Y, Hasegawa M, Igarashi N, et al. Cutaneous manifestations and histological features of microscopic polyangiitis. Eur $\mathbf{J}$ Dermatol. 2009; 19: 57-60.

97. Birnbaum J, Danoff S, Askin FB, Stone JH. Microscopic polyangiitis presenting as a "pulmonary-muscle" syndrome: Is subclinical alveolar hemorrhage the mechanism of pulmonary fibrosis? Arthritis Rheum. 2007; 56: 2065-71.

98. Mantegani A, Aubert J, Guelpa G. [Inflammatory myopathy: unusual presentation of a case of Wegener disease]. Schweiz Med Wochenschr. 1993; 123: 1996-2000.

99. Salam A, Meligonis G, Malhotra R. Superior oblique myositis as an early feature of orbital Wegener's granulomatosis. Orbit. 2008; 27: 203-6.

100. Colmegna I, Maldonado-Cocco JA. Polyarteritis nodosa revisited. Curr Rheumatol Rep. 2005; 7: 288-96.

101. Plumley SG, Rubio R, Alasfar S, Jasin HE. Polyarteritis nodosa presenting as polymyositis. Semin Arthritis Rheum. 2002; 31: 377-83. 
102. Yang SN, Cho NS, Choi HS, et al. Muscular polyarteritis nodosa. J Clin Rheumatol. 2012; 18: 249-52.

103. Hall C, Mongey AB. Unusual presentation of polyarteritis nodosa. J Rheumatol. 2001; 28: 871-3.

104. Hernández-Rodríguez J, Alba MA, PrietoGonzález S, Cid MC. Diagnosis and classification of polyarteritis nodosa. J Autoimmun. 2014; 48-49: 84-9.

105. Cid MC, Grau JM, Casademont J, et al. Immunohistochemical characterization of inflammatory cells and immunologic activation markers in muscle and nerve biopsy specimens from patients with systemic polyarteritis nodosa. Arthritis Rheum. 1994; 37: 1055-61.

106. Lie JT. Systemic and isolated vasculitis. A rational approach to classification and pathologic diagnosis. Pathol Annu. 1989; 24 Pt 1: 25-114.

107. Matsubara S, Mair WG. Ultrastructural changes of skeletal muscles in polyarteritis nodosa and in arteritis assoicated with rheumatoid arthritis. Acta Neuropathol. 1980; 50: 169-74.

108. Izumi Y, Miyashita T, Kitajima T, et al. Two cases of refractory polymyositis accompanied with steroid myopathy. Mod Rheumatol. 2014 [Epub ahead of print].

109. Walsh RJ, Amato AA. Toxic myopathies. Neurol Clin. 2005; 23: 397-428.

110. Dekhuijzen PN, Decramer M. Steroid-induced myopathy and its significance to respiratory disease: a known disease rediscovered. Eur Respir J. 1992; 5: 997-1003.

111. Pereira RMR, de Carvalho J. Glucocorticoid-induced myopathy. Joint Bone Spine Rev Rhum. 2011; 78: 41-4.

112. Zirin J, Nieuwenhuis J, Perrimon N. Role of autophagy in glycogen breakdown and its relevance to chloroquine myopathy. PLoS Biol. 2013; 11: e1001708.

113. Abdel-Hamid H, Oddis CV, Lacomis D. Severe hydroxychloroquine myopathy. Muscle Nerve. 2008; 38: 1206-10.

114. Estes ML, Ewing-Wilson D, Chou SM, et al. Chloroquine neuromyotoxicity. Clinical and pathologic perspective. Am J Med. 1987; 82: 447-55.

115. Finsterer J, Jarius C. Increased CSF protein in chloroquine-induced axonal polyneuropathy and myopathy. Clin Neurol Neurosurg. 2003; 105: 231-6.

116. Katzberg HD, Kassardjian CD. Toxic and endocrine myopathies. Contin Lifelong Learn Neurol. 2016; 22: 1815-28.

117. Fernandez C, Figarella-Branger D, Alla P, et al. Colchicine myopathy: a vacuolar myopathy with selective type I muscle fiber involvement. An immunohistochemical and electron microscopic study of two cases. Acta Neuropathol. 2002; 103: 100-6.

118. Breil M, Chariot P. Muscle disorders associated with cyclosporine treatment. Muscle Nerve. 1999; 22: 1631-6.

119. Goy JJ, Stauffer JC, Deruaz JP, et al. Myopathy as possible side-effect of cyclosporin. Lancet (London, England). 1989; 1: 1446-7.

120. Grezard O, Lebranchu Y, Birmele B, et al. Cyclosporin-induced muscular toxicity. Lancet (London, England). 1990; 335: 177.

121. Petersen J, Halberg P, Højgaard K, Lyon BB, Ullman S. Penicillamine-induced polymyositis-dermatomyositis. Scand J Rheumatol. 1978; 7: 113-7.

122. Baer AN, Wortmann RL. Myotoxicity associated with lipid-lowering drugs. Curr Opin Rheumatol. 2007; 19: 67-73.

123. Thompson PD, Clarkson P, Karas RH. Statin-associated myopathy. JAMA. 2003; 289: 1681-90.

124. Pasternak RC, Smith SC, Bairey-Merz CN, et al. ACC/AHA/NHLBI clinical advisory on the use and safety of statins. Circulation. 2002; 106: 1024-8.

125. Christopher-Stine L, Casciola-Rosen LA, Hong G, et al. A novel autoantibody recognizing $200-\mathrm{kd}$ and $100-\mathrm{kd}$ proteins is associated with an immune-mediated necrotizing myopathy. Arthritis Rheum. 2010; 62: 2757-66.

126. Grable-Esposito P, Katzberg HD, Greenberg $\mathrm{SA}$, et al. Immune-mediated necrotizing myopathy associated with statins. Muscle Nerve. 2010; 41: 185-90.

127. Meriggioli MN, Barboi AC, Rowin J, Cochran EJ. HMG-CoA reductase inhibitor myopathy: clinical, electrophysiological, and pathologic data in five patients. J Clin Neuromuscul Dis. 2001; 2: 129-34.

128. Phillips PS, Haas RH, Bannykh S, et al. Statin-associated myopathy with normal creatine kinase levels. Ann Intern Med. 2002; 137: 581-5.

129. Exeter D, Connell DA. Skeletal muscle: functional anatomy and pathophysiology. Semin Musculoskelet Radiol. 2010; 14: 97-105. 